Journal of

Stem Cell Reports

\title{
Assembly of Size Selective Multicellular Spheroids of Adipose-Derived Stem/ Stromal Cells for Use in Regenerative Tissue Engineering: A Methods and Mor- phologic Study
}

\author{
John D. Murray MD, FACS ${ }^{1, *}$, Bharani Krishna Mynampati Ph.D ${ }^{2}$, Jason Brant Ph.D ${ }^{3}$, Abby Sheffield DO ${ }^{4}$, \\ Marie Crandall MD, MPH, FACS ${ }^{5}$, Edward W. Scott Ph.D ${ }^{6}$
}

${ }^{1}$ University of Florida at Jacksonville, Division of Plastic Surgery, The Regenerative Medicine Laboratory, Jacksonville, FL, USA

${ }^{2}$ University of Florida at Jacksonville, Department of OphthalmologyJacksonville, FL, USA

${ }^{3}$ University of Florida at Gainesville, Department of Medicine, Gainesville, FL, USA

${ }^{4}$ Department of Surgery, Jacksonville, FL, USA

${ }^{5}$ University of Florida at Jacksonville, Department of Surgery, Jacksonville, FL, USA

${ }^{6}$ University of Florida at Gainesville, Department of Microbiology and Molecular GeneticsGainesville, FL, USA

${ }^{*}$ Corresponding author: John Murray, MD, FACS, 653 West 8th Street, Faculty Bldg., 3rd floor, Jacksonville, FL 32209, 904-2443915, Fax 904-244-3870; Email: john.murray@jax.ufl.edu

Received Date: November 24, 2019 Accepted Date: December 14, 2019 Published Date: December 17, 2019

Citation: John D. Murray (2019) Assembly of Size Selective Multicellular Spheroids of Adipose-Derived Stem/Stromal Cells for Use in Regenerative Tissue Engineering: A Methods and Morphologic Study. J Stem Cell Rep. 1: 1-9.

\begin{abstract}
As regenerative scaffolds exhibit varying pore sizes, producing adipose-derived stem/stromal cell (ASC) spheroids of selective sizes to populate these pores may be helpful in autologous tissue engineering. Herein we present two protocols for the initial magnetic sorting of ASCs and the subsequent size selective assembly of ASC spheroids; as the critical quality attribute of ASC identity has been shown previously, only spheroid morphology will be studied. Paramagnetic microbeads (Protein G ligand Dynabeads ${ }^{\oplus}$, Thermo Fisher Scientific) were used to create single-core paramagnetic immunobeads (scPIBs) and dual core paramagnetic immunobeads (dcPIBs). The scPIBs were created by conjugating the paramagnetic microbeads to ASC-selective primary antibodies (mouse antihuman CD 44, CD73, CD90, CD105, BD Biosciences). The dcPIBs were created by initially conjugating the paramagnetic microbeads to secondary antibodies (mouse IgG) and then conjugating the secondary antibodies to the same ASC-selective primary antibodies. The scPIBs and dcPIBs were then admixed within 15 $\mathrm{ml}$ of fresh lipoaspirate respectively. The ASC-scPIBs and ASC-dcPIBs were then magnetically precipitated and subsequently cultured in low adherent conditions for five days. Within twenty minutes, scPIBs isolated an average of 1.2 million putative ASCs ( 8 x 104 cells per $\mathrm{ml}$ of lipoaspirate processed) and dcPIBs isolated an average of 1.3 million putative ASCs (8.7 x 104 cells per $\mathrm{ml}$ of lipoaspirate processed). Spheroids comprised of ASC-scPIBs were $19.3 \mu \mathrm{m}$ (average, $+/-5 \mu \mathrm{m}$ ) and spheroids of the ASC-dcPIBs were $216.7 \mu \mathrm{m}$ (average, $+/-25 \mu \mathrm{m}$ ). ASCs were magnetically precipitated from fresh lipoaspirate in twenty minutes and subsequently underwent self-assembly of small (approximately $20 \mu \mathrm{m}$ ) or large (approximately $220 \mu \mathrm{m}$ ) ASC spheroids over five days. These protocols may be useful in the rapid development of size-selectable ASC spheroids, which may be particularly useful for autologous toxicology, pharmacology, disease modeling, and tissue regeneration.
\end{abstract}

Keywords: Mesenchymal stem cells; adipose-derived stem cells; adipose-derived stem/stromal cells; regenerative medicine; spheroids; organoids; scaffolds; ASCs.

C 2019 The Authors. Published by the JScholar under the terms of the Creative Commons Attribution License http://creativecommons.org/licenses/ by $/ 3.0 /$, which permits unrestricted use, provided the original author and source are credited. 


\section{Abbreviations}

MSC=mesenchymal stem cell; ASC $=$ adipose-derived stem/stromal cell; $\mathrm{PIB}=$ paramagnetic immunobead; $\mathrm{scPIB}=$ single core paramagnetic immunobead; $\mathrm{dcPIB}=$ dual core paramagnetic immunobead; ECM= extracellular matrix

\section{Introduction}

Tissue engineering relies on three fundamental and synergistic ingredients: a scaffold, cells, and growth factors. Scaffolds used in tissue fabrication are commonly porous, biocompatible, and biodegradable materials that provide complementary structural and biochemical micro environments $[1,2]$. The void cavities, or pores, within the scaffold help determine the level of functional biological activity within the engineered tissue for regenerative applications $[3,4]$. The structure of the pores offers initial anchoring of cells while the size, design, and network of the pores play essential roles in cell nutrition, proliferation, angiogenesis, gene expression, and capacity for tissue regeneration $[3,5,6]$ In essence, cell behavior is directly affected by the cell seeding density and the scaffold architecture as the porous extracellular matrix (ECM) provides cues that influence the integrin-ligand communications between cells, the ECM, and surrounding biofactors [7-10].

While several methods for scaffold-based cell culturing have been developed since becoming widely popular about 30 years ago, [11] scaffold-free 3-dimensional culturing started more than 100 years ago. The American embryologist Ross Harrison at Johns Hopkins Medical School has been commonly credited with the development of in vitro3-dimensional tissue culture in 1907. In this technique, he maintained frog embryo nerve fibers in vitro by a method he described as the "hanging drop" technique [12]. The embryonic frog nerve tissues were cultured in a clot of lymphatic fluid adherent to the underside of a plastic plate, commonly up to 5 weeks.

In 1911, Alexis Carrel, a French surgeon and biologist at Rockefeller Institute (he himself the 1912 Nobel Prize laureate in Physiology or Medicine for his pioneering work on vascular suturing techniques) and his assistant Montrose Burrows coined the term "tissue culture" [13]. They adapted Harrison's hanging drop technique but used blood plasma instead of lymph to sustain amphibian embryonic cells, or "small fragments of living tissue," for longer growth duration [14]. The hanging drop technique has since become widely used for culturing of multicellular aggregates, commonly termed multicellular spheroids, or spheroids, from cell suspensions $[15,16]$.
The discovery of 3-dimensional tissue culturing by Harrison and subsequent improvements by Carrel and Montrose were critical events in tissue engineering as we now know spheroids exhibit physiologic properties more closely mimicking in vivo cellular processes than their 2-dimensional culture counterparts $[15,17]$. In fact, compared to 3 -dimensional culturing, mesenchymal stem cells undergo quick loss of plasticity during 2-dimensional expansion alone [18]. Thus, populating a scaffold with cells within spheroids, versus disbursed cells, may afford a more robust micro environment for hormonal or structural regenerative medicine [19].

For scaffold-based tissue engineering with spheroids, the spheroids must be compatible with the size of the scaffold pores to produce the desired tissue properties. Cell behavior has been shown to be directly affected by the scaffold pore size and architecture [20]. For example, smaller pores (generally less than $200 \mu \mathrm{m}$ ) enable cell adhesion and faster cellular ingrowth while larger pores (generally greater than $800 \mu \mathrm{m}$ ) enable greater vascularization, nutrient transport, and cell migration [21].

In addition to the contemporary hanging drop method, [22-24] several methods for scaffold-free spheroid culturing have been developed [25]. Examples include the application of low-adhesive substrates to flat plate cultures, 26 chitosan membrane based aggregation, [27,28] and forced aggregation [29]. However, spheroid culturing methods typically produce spheroids of varying and unpredictable sizes [30]. Thus, scaffold-based culturing may be optimized with size-selected spheroids to populate scaffold pores of specific sizes.

For the purposes of regenerative medicine, cell composition within the spheroid must be considered. Mesenchymal stem cells (MSCs) exhibit the unique ability to differentiate along endodermal, mesodermal, and ectodermal pathways. Accordingly, they are useful in regenerative complex tissue engineering. Spheroids of MSCs have been used in stem cell biological research, [31-34] tissue engineering, [35-37] and oncology $[17,38]$. As such, MSC spheroids may be better physiologically suited for complex tissue engineering in scaffold-based regenerative systems than MSC suspensions [25,39] Adipose-derived stem/stromal cells (ASCs), mesenchymal stem cells residing in adipose tissue, are easily obtained in immediately useful quantities without expansion compared to MSCs isolated from bone marrow. Herein we present two protocols for the initial magnetic sorting of ASCs and the subsequent size-selectable assembly of ASC spheroids; as we have shown the critical quality attribute of ASC identity with similar immunoprecipitation, only spheroid morphology will be studied [42]. 


\section{Materials and Methods}

\section{Lipoaspirate harvest}

Fresh human lipoaspirate obtained from informed and consented healthy females were used for this study (University of Florida Jacksonville Institutional Review Board approved the study, IRB\# 201601520). The lipoaspirate was harvested using a standard operative tumescent technique using syringe liposuction. The tumescent solution included normal saline, lidocaine, and epinephrine. Shortly after harvest, the fresh lipoaspirate underwent 20 intersyringe transfers (10 $\mathrm{ml}$ syringes). After separating into principally aqueous and adipose layers, the aqueous layer was decanted. The remaining adipose layers were combined for a total working volume of $15 \mathrm{ml}$. This study incorporated triple biological replicates and triple technical replicates [40,41].

\section{Programming of scPIBs and dcPIBs}

\section{Preparation of PIBs}

The scPIBs and dcPIBs were prepared to recognize a panel of ASC cell surface markers (CD44, CD73, CD90, and CD105) using the Dynabead ${ }^{\circledR}$ protein $\mathrm{G}$ immunoprecipitation kit (Thermo Fisher Scientific, Waltham, MA, cat\#10007D). Additionally, a $50 \mu \mathrm{L}$ aliquot of the protein G Dynabeads ${ }^{\circledR}$ (previously conjugated to protein $G$, as supplied from the manufacturer) were used for each immunoprecipitation event. To initially prepare one Dynabead ${ }^{\oplus}$ aliquot, $50 \mu \mathrm{L}$ of Dynabead $^{\circledR}$ was placed in a microfuge tube. A neodymium magnet $(3 \times 0.2 \times 0.5$ inch, Omega Magnets, Carpentaria, CA) was then placed next to the tube to precipitate the beads and the supernatant was removed. $200 \mu \mathrm{L}$ of antibody binding and washing buffer was then placed in the microfuge tube to resuspend the beads.

\section{Programming of scPIBs}

To each aliquot of protein G Dynabeads ${ }^{\oplus}, 5 \mu \mathrm{L}$ of mouse anti-human IgG antibodies of markers CD44, CD73, CD90, and CD105 (BD Biosciences, Franklin Lakes, NJ, cat\#562245), diagnostic for ASC enrichment, were added and incubated in rotation $\left(360^{\circ}\right.$ rotation, HulaMixer ${ }^{\oplus}$, Thermo Fisher Scientific, cat\#15920D) for 10 minutes at room temperature, creating scPIBs. The supernatant was then removed after paramagnetic immunoprecipitation and $200 \mu \mathrm{L}$ of the washing buffer was added and the scPIBs were briefly vortexed to homogeneous suspension. A structural scPIB diagram is seen in figure 1-A.

\section{Programming of dcPIBs}

To each aliquot of protein G Dynabeads ${ }^{\oplus}, 5 \mu \mathrm{L}$ of rabbit anti-mouse IgG antibody (Thermo Fisher Scientific, cat\# A27022) was initially added. The suspension was then rotated exactly the same for the programming of scPIBs. The Dynabeads ${ }^{\circledast}$ were then precipitated with the magnet and the supernatant was removed and $200 \mu \mathrm{L}$ of the washing buffer was added. Then, 5 $\mu \mathrm{L}$ each of the mouse anti-human IgG antibodies of markers CD44, CD73, CD90, and CD105, the same antibodies used to program scPIBs, were added to the tube and incubated in rotation, creating dcPIBs. The supernatant was then removed after magnetic immunoprecipitation and $200 \mu \mathrm{L}$ of the washing buffer was added and the dcPIBs were briefly vortexed to homogeneous suspension. A structural dcPIB diagram is seen in figure 1-B.
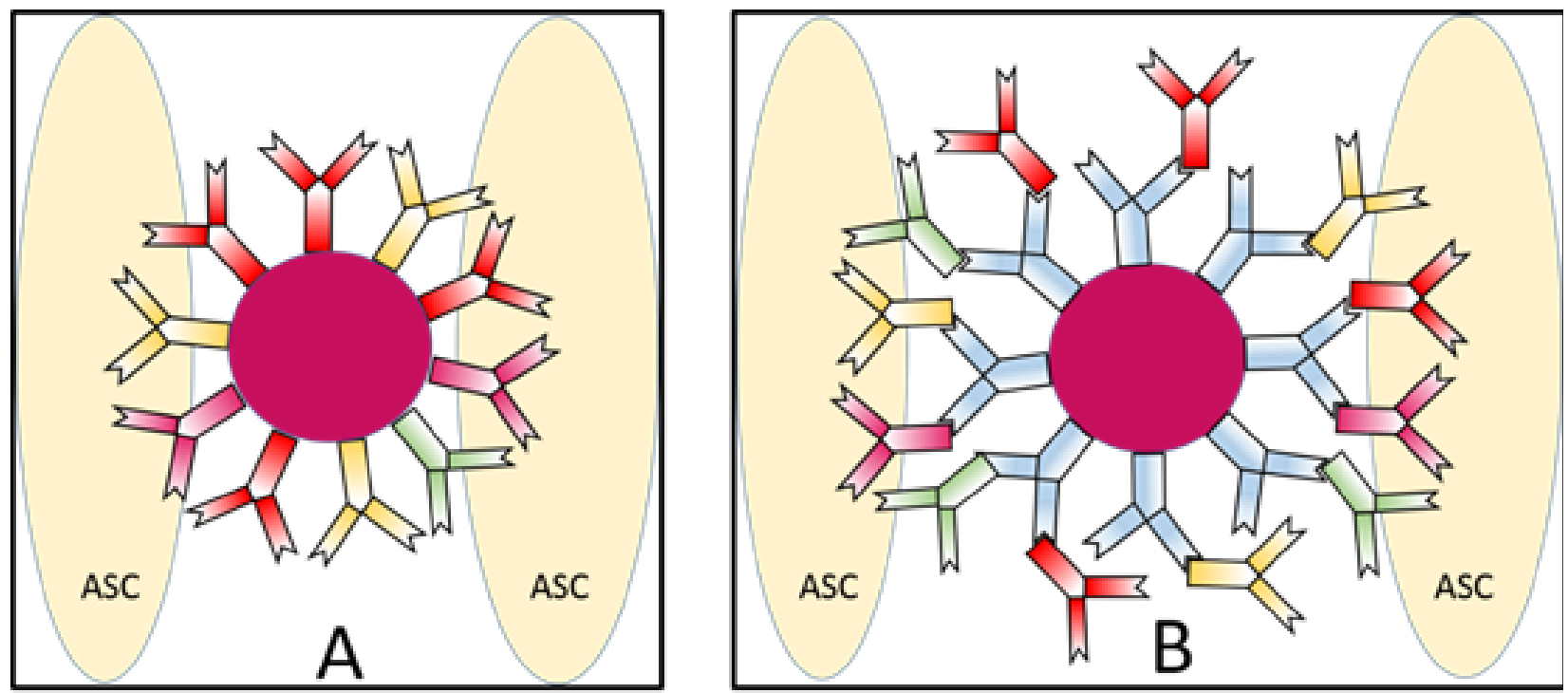

Figure 1. Paramagnetic immunobeads (PIBs). 
Figure 1 A. Single core PIB structure. The paramagnetic bead (magenta center) is linked to four different antibodies (CD44, CD73, CD90, and CD105) which are diagnostic for adipose-derived stem cells (ASCs). The antibodies are attached to the bead via a Protein G linker.

Figure 1 B. Dual core PIB structure. The proteomic structure remains the same as the single core PIB except that secondary antibodies (blue) are linked initially to the PIB, and then to the identical primary antibodies used in the single core design.

\section{ASC-scPIB and ASC-dcPIB immunoprecipitation}

The $15 \mathrm{mls}$ of lipoaspirate was added to an empty $15 \mathrm{~mL}$ polypropylene coned tube and the $200 \mu \mathrm{L}$ suspension of either scPIBs or dcPIBs was added to the tube. The tube was capped and then held and rotated in hand for 10 minutes. With the tube returned to the upright position, the magnet was then placed parallel and adjacent to the long axis of the tube. Over the next 10 minutes, the magnet was steadily moved toward the coned bottom of the tube to precipitate the ASC-scPIBs or ASC-dcPIBs respectively to the bottom of the coned tube. The lipoaspirate was then discarded and the ASC-PIBs were respectively resuspended in $1 \mathrm{~mL}$ of Dulbecco's phosphate buffered saline (STEMCELL Technologies, cat\#37350) for subsequent cell counting and culture. No attempt to unconjugate the PIBs from the ASCs was made. Cells were evaluated for viability using trypan blue exclusion and were counted using a Neubauerdesigned hemocytometer chamber.

\section{ASC-scPIB and ASC-dcPIB culturing and self-assembly}

Approximately 200,000 of either ASC-scPIBs or ASCdcPIBs were added to each well of a 6-well sterile culture plate (VWR, \#15705-056, without attachment substrate); each well also contained $2 \mathrm{mls}$ of animal component free defined media (MesenCult-ACF basal medium \#05451 and 5X supplement \#05452, STEMCELL Technologies, Vancouver, BC). Each plate was incubated at humidified 5\% carbon dioxide and left undisturbed. On culture day 5, microscopic evaluation was completed and recorded. Each well underwent phase contrast microscopy and spheroids were manually counted in each well. Photomicrographs were obtained using a $16 \mathrm{MP}$ trans-ocularcamera (CoolpixS7000, Nikon, Melville, NY) and subsequently analyzed (PowerPoint 15.27, Microsoft, Redmond, WA). Each photograph included the equatorial ocular limits as this served as an absolute reference. At each power of magnification, reference sizing fields were similarly obtained using a Neubauer designed hemocytometer. Images of the spheroids were then overlaid onto the reference sizing field images for accurate measurement using the PowerPoint software. The entirety of each well was micro- scopically evaluated.

\section{Results}

Three separate ASC-scPIB samples and three separate ASC-dcPIB samples were obtained (six different patients) and plating included triple technical replicates each. We have reported respective ASC-dcPIB immunoprecipitation, morphology evaluation, and functional testing (tri-lineage differentiation and immunocytochemistry) previously [42]. Such attempt to repeat such a study for the respect of scPIBs was not undertaken except for microscopic morphology.

Programming of the scPIBs or dcPIBs and immunoprecipitation took 30 minutes or less. scPIBs isolated an average of 1.2 million putative ASCs (or $8 \times 104$ cell per ml of lipoaspirate processed) and dcPIBs isolated an average of 1.3 million putative ASCs (or 8.7 x 104 cells per $\mathrm{ml}$ of lipoaspirate processed). Spheroids comprised of ASC-scPIBs were $19.3 \mu \mathrm{m}$ (average, $+/-5 \mu \mathrm{m}$ ) and spheroids of ASC-dcPIBs were $216.7 \mu \mathrm{m}$ (average, +/- 25 $\mu \mathrm{m})$. Accordingly, for study nomenclature, ASC-scPIB spheroids are named micro-spheroids and ASC-dcPIB spheroids are named macro-spheroids. (See figures 2 and 3 ).

The morphology of each spheroid was predominantly spherical in shape and minimally anchored to the plate, if at all. Certainly not all of the PIBs attached to nucleated cells (one can see the free beads as tiny green dots in figure 2-A/B) and very rare micro-spheroids were appreciated in wells containing dcPIBs. As an interesting corollary, the scPIBs produced a total of 200 micro-spheroids on average per well and the dcPIBs produced six macro-spheroids on average per well. Thus, based on the observed diameters appreciated in two dimensions, the scPIBs produced 33 million cubic $\mu \mathrm{m}$ per well and the dcPIBs produced 49 million cubic $\mu \mathrm{m}$ per well (or 32\% more spheroid total volume).

If the spheroids were allowed to grow beyond 5 days, there was no appreciable size change though they did become seemingly adherent to one another. 

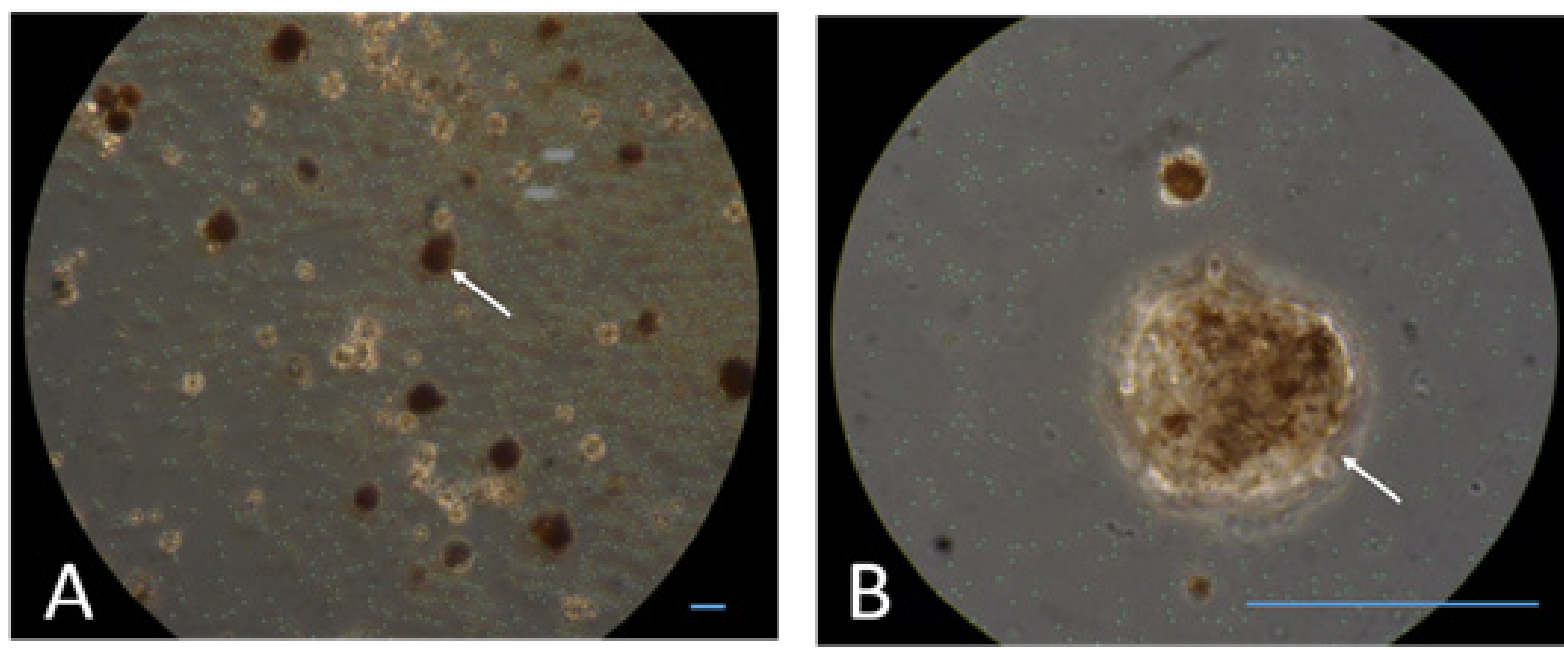

Figure 2. Adipose-derived stem cell(ASC) spheroids self-assemble after ASC-paramagnetic bead (aPIB) immunoprecipitation as seen under phase-contrast microscopy at culture day 5.

A. ASC micro-spheroids (arrow). These micro-spheroids self-assembled with the aid of single core PIBs. The average micro-spheroid diameter is approximately $20 \mu \mathrm{m}(+/-5 \mu \mathrm{m})$. The measurement bar is $25 \mu \mathrm{m}$ (40x mag.).

B. ASC macro-spheroid (arrow). These macro-spheroids self-assembled with the aid of dual core PIBs. The average macro-spheroid diameter is approximately $220 \mu \mathrm{m}(+/-25 \mu \mathrm{m})$. The measurement bar is $250 \mu \mathrm{m}$ (10x mag.). [Note that the free immunobeads appear green whilst the spheroids appear dark brown (which is closer to the dark magenta color of these immunobeads)].

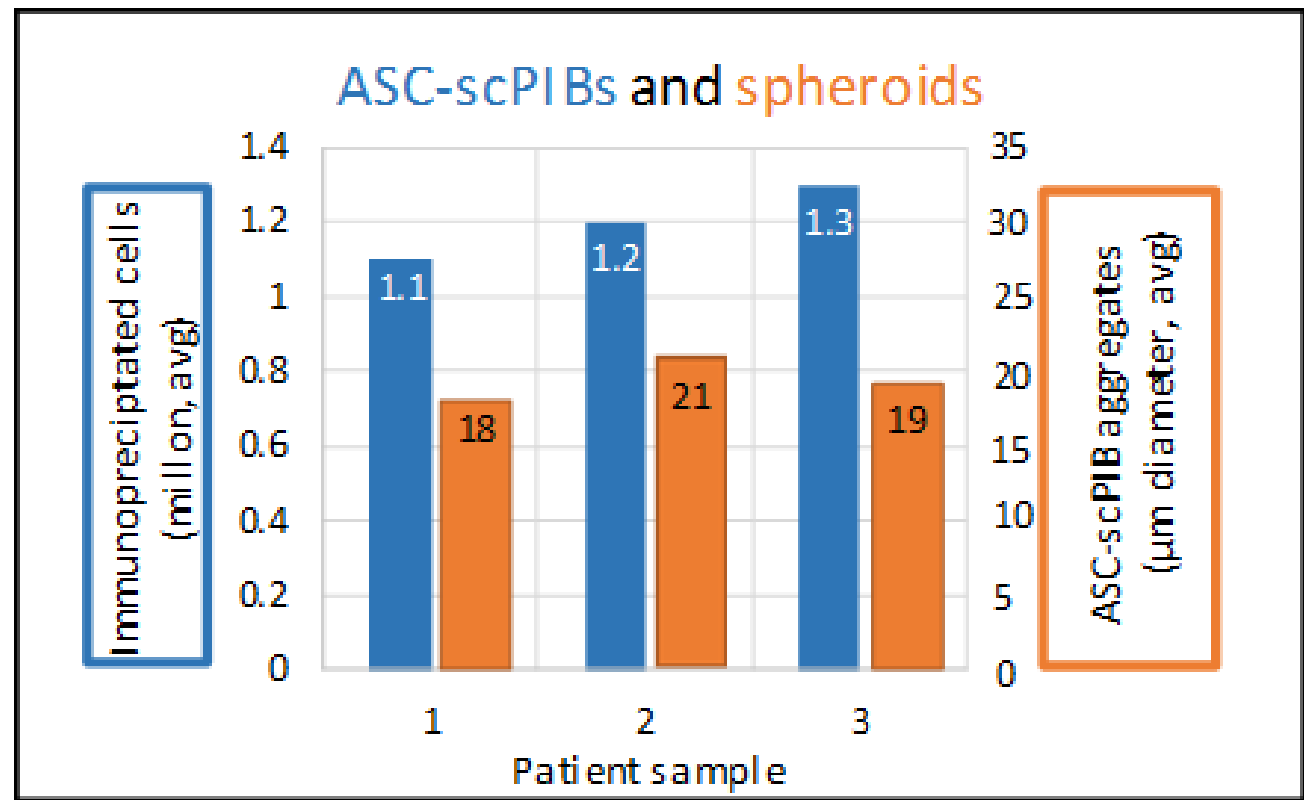




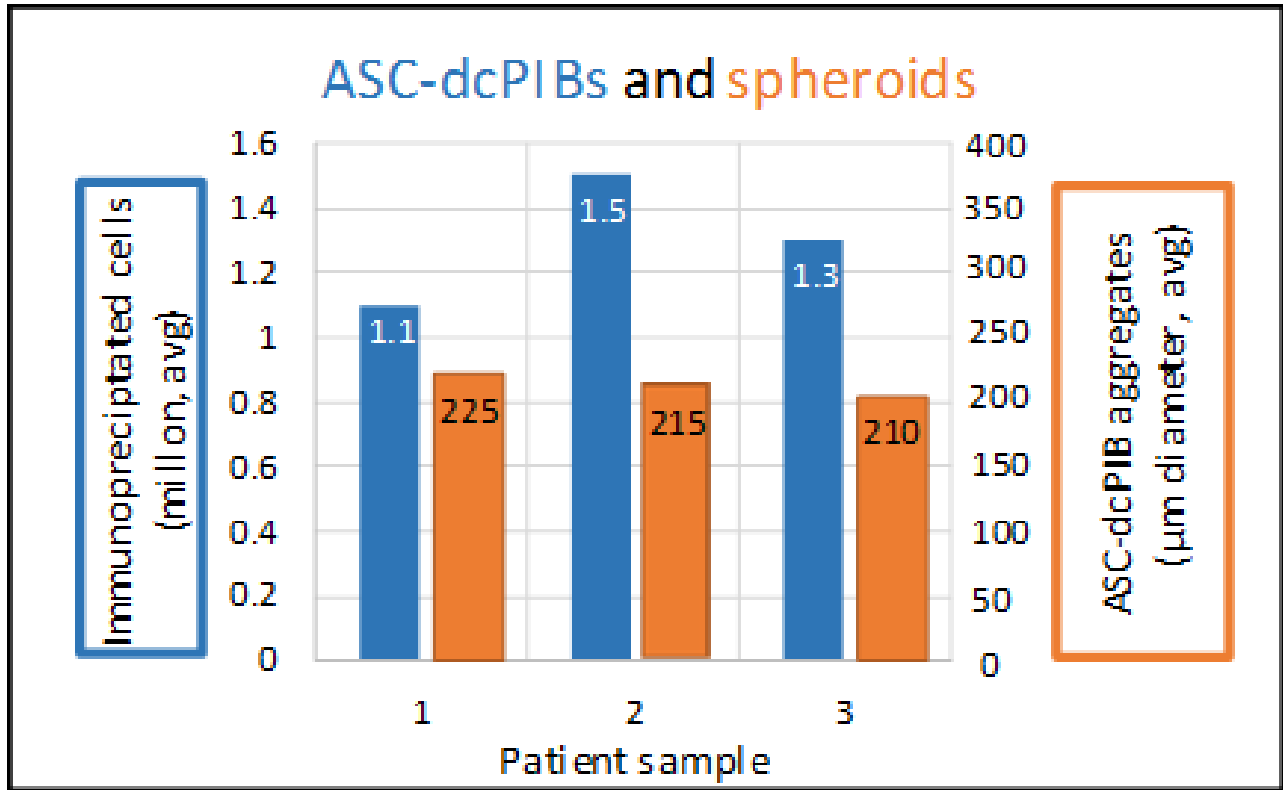

Figure 3. Quantities of adipose-derived stem cells (ASCs) and subsequent spheroid diameter using single core paramagnetic immunobeads (scPIBs, top panel) and dual-core paramagnetic immunobeads (dcPIBs, bottom panel)].

\section{Discussion}

The development of complex soft tissues, tissues composed of cells of several lineage-specific subtypes, pose tremendous benefits for regenerating and replacing diseased, degenerating, and otherwise absent native tissues. The ideal engineered complex soft tissue would assume the perfect form and function of the target host tissues. As autologous ASCs are capable of differentiating into several multi-lineage cell subtypes, they may be particularly useful, if not necessary, components of an autologous regenerative scaffold system. Additionally, ASC spheroids have been shown to enhance anti-inflammatory and angiogenic properties of MSCs, $[43,44]$ increase stemness, $[45,46]$ facilitate lineage differentiation and improve cell survival after engraftment [44].

As ASCs within spheroids exhibit physiologic properties more closely related to in vivo tissues than 2-dimensional ASC cultures, [47] applying ASC spheroids to scaffolds to optimize the molecular and proteomic potential of the ASC spheroids may produce more rapid hormonal or structural regenerative effects $[23,48]$. However, scaffold properties to include modulus, permeability, and porosity must be accounted for to optimize ASC function. Therefore, dependent on these structural properties, selecting a spheroid size to populate the scaffold may be of particular importance.

While many contemporary tissue engineering protocols utilize induced pluripotent stem cells (iPSCs), or somatic cells reprogrammed to pluripotency by viral vectors within the nucleus, the use of autologous multipotent ASCs pose several unique benefits. The most practical benefit for the use of autologous ASCs is the fact that they may be harvested and used potentially at the point-of-care, instead of undergoing the increased time and complexity needed for reprogramming in the laboratory. The stromal origin of ASCs also portend quick scaffold adhesion in culture and fast proliferation rates without karyotype alterations over several culture passages [49]. Additionally, as demonstrated in vitro, ASCs may differentiate into several cell types of the mesodermal, ectodermal, and endodermal lineages as their plasticity is driven by the ECM and local soluble growth factors [19,50-53]. Further advantages for the clinical application of ASCs include ease of isolation and high yield, the ability to mediate inflammation and to promote cell growth, cell differentiation, and tissue repair by immune-modulation and immune-suppression, recusal from ethical implications, and no known association for teratoma formation $[54,55]$.

We have previously shown that dual-core paramagnetic immunobeads (dcPIBs), or paramagnetic microbeads with a dual-core of antibodies, the outer core of which is diagnostic for ASCs, precipitate ASCs from adipose tissue as a positive selection assay [42]. The dual layering of antibodies stemmed from our initial suspicion that the dual-core may reduce the steric hindrance of the variable IgG regions of the outer core antibodies to improve dcPIB-ASC binding capacity and improve the efficacy of the precipitation. In actuality, the quantity of precipitated putative ASCs was very similar between the single and dual microbead methods; however, as an observation, each method produced drastically different sized ASC spheroids (scPIB spheroids being 
about 10 times smaller than $\mathrm{dcPIB}$ spheroids). We are unaware of a similar technique for positive selective immunoprecipitation of ASCs and subsequent spheroid formation; however, superparamagnetic nanoparticles have been used to create MSC spheroids of uncontrollable size via non-selective "magnetic levitation" once the MSCs are placed in suspension [56-58].

Another interesting observation is that scPIBs and $\mathrm{dcPIBs}$ are seemingly bound to ASCs in spheroids for much longer duration than to ASCs in 2-dimensional culture. In 2-dimensional culture, most PIBs are unconjugated form ASCs by culture day 5, whereas in spheroid culture, PIBs were still bound to ASCs even at culture day 30. While cellular senescence or cell division/ replication would unconjugatePIBs from the ASCs, one could conclude that these respective cellular processes are not undertaken in similar physiologic patterns in spheroids comparative to flat plate culture. In fact, MSCs cultured as 3D multicellular spheroids are known to maintain cell-cell interactions and become quiescent [59]. Functional studies of the PIB-ASC spheroids will need to be completed as well as causal mechanisms that lead to these spheroids.

\section{Conclusions}

The use of scPIBs and dcPIBs precipitated ASCs from lipoaspirate and produced small (approximately $20 \mu \mathrm{m}$ ) and large (approximately $220 \mu \mathrm{m}$ ) ASC spheroids respectively. Populating scaffold pores with size-selective ASC spheroids may improve the function of these constructs for tissue engineering and regeneration.

\section{Acknowledgments}

I wish to thank Ms. Jennifer Mull and Mr. Yohan Zuniga for their services as nurse coordinators for this study.

\section{References}

1. Tsang VL, Bhatia SN (2004) Three-dimensional tissue fabrication. Adv Drug Deliv Rev 56: 1635-1647.

2. Chevalier E, Chulia D, Pouget C, Viana M (2008) Fabrication of porous substrates: A review of processes using pore forming agents in the biomaterial field. J Pharm Sci 97:1135-1154.

3. Hollister SJ (2005) Porous scaffold design for tissue engineering. Nat Mater 4: 518-524.

4. Kang H, Hollister S, Lin C (2010) Topology optimization of three dimensional tissue engineering scaffold architectures for prescribed bulk modulus and diffusivity. Structural and Multidisciplinary Optimization 42: 633--644.

5. Causa F, Netti PA, Ambrosio L (2007) A multi-functional scaffold for tissue regeneration: The need to engineer a tissue analogue. Biomaterials 28: 5093-5099.

6. Sart S, Schneider YJ, Li Y, Agathos SN (2014) Stem cell bioprocess engineering towards cGMP production and clinical applications. Cytotechnology. 66: 709-722.

7. Murphy CM, Haugh MG, O'Brien FJ (2009) The effect of mean pore size on cell attachment, proliferation and migration in collagen-glycosaminoglycan scaffolds for bone tissue engineering. Biomaterials 31: 461-466.

8. Yassin MA, Leknes KN, Pedersen TO, et al. (2015) Cell seeding density is a critical determinant for copolymer scaffolds-induced bone regeneration. J Biomed Mater Res A 103: 3649-3658.

9. Wang L, Seshareddy K, Weiss ML, Detamore MS (2009) Effect of initial seeding density on human umbilical cord mesenchymal stromal cells for fibrocartilage tissue engineering. Tissue Eng Part A 15: 1009-1017.

10. Vo TN, Tabata Y, Mikos AG (2016) Effects of cellular parameters on the in vitro osteogenic potential of dual-gelling mesenchymal stem cell-laden hydrogels. J BiomaterSciPolym Ed 27: 1277-1290.

11. Langer R, Vacanti JP (1993) Tissue engineering. Science 260: 920-926.

12. Nicholas J. Ross granville harrison (1961) Washington: National Academy of Sciences.

13. Carrel A, Burrows MT (1911) Cultivation of tissues in vitro and its technique. J Exp Med 13: 387-396.

14. Carrel A, Burrows MT (1911) An addition to the technique of the cultivation of tissues in vitro. J Exp Med 14: 244-247.

15. Layer PG, Robitzki A, Rothermel A, Willbold E (2002) Of layers and spheres: The reaggregate approach in tissue engineering. Trends Neurosci 25: 131-134.

16. Kurosawa H (2007) Methods for inducing embryoid body formation: In vitro differentiation system of embryonic stem 
cells. J BiosciBioeng 103: 389-398.

17. Mueller-Klieser W (1997)Three-dimensional cell cultures: From molecular mechanisms to clinical applications. Am J Physiol 273: C1109-23.

18. Zomer HD, Vidane AS, Goncalves NN, Ambrosio CE (2015) Mesenchymal and induced pluripotent stem cells: General insights and clinical perspectives. Stem Cells Cloning 8:125-134.

19. Marquez-Curtis LA, Janowska-Wieczorek A, McGann LE, Elliott JA ( 2015) Mesenchymal stromal cells derived from various tissues: Biological, clinical and cryopreservation aspects. Cryobiology 71:181-197.

20. Murphy CM, Haugh MG, O'Brien FJ (2010) The effect of mean pore size on cell attachment, proliferation and migration in collagen-glycosaminoglycan scaffolds for bone tissue engineering. Biomaterials 31:461-466.

21. Joly P, Duda GN, Schone M, et al. (2013) Geometry-driven cell organization determines tissue growths in scaffold pores: Consequences for fibronectin organization. PLoS One 8: e73545. 22. Bartosh TJ, Ylostalo JH, Mohammadipoor A, et al. (2010) Aggregation of human mesenchymal stromal cells (MSCs) into 3D spheroids enhances their antiinflammatory properties. Proc Natl Acad Sci USA 107: 13724-13729.

23. Suzuki S, Muneta T, Tsuji K, et al. (2012) Properties and usefulness of aggregates of synovial mesenchymal stem cells as a source for cartilage regeneration. Arthritis Res Ther 14: R136.

24. Bartosh TJ, Ylostalo JH (2014) Preparation of anti-inflammatory mesenchymal stem/precursor cells (MSCs) through sphere formation using hanging-drop culture technique. CurrProtoc Stem Cell Biol 28: Unit 2B.6.

25. Cesarz Z, Tamama K (2016) Spheroid culture of mesenchymal stem cells. Stem Cells Int 2016: 9176357.

26. Lee JH, Han YS, Lee SH (2016) Long-duration three-dimensional spheroid culture promotes angiogenic activities of adipose-derived mesenchymal stem cells. BiomolTher (Seoul) 24 260-267.

27. Cheng NC, Wang S, Young TH (2012) The influence of spheroid formation of human adipose-derived stem cells on chitosan films on stemness and differentiation capabilities. Biomaterials 33: 1748-1758.

28. Yeh HY, Liu BH, Sieber M, Hsu SH (2014) Substrate-dependent gene regulation of self-assembled human MSC spheroids on chitosan membranes. BMC Genomics 15: 10-2164-15-10.

29. Zimmermann JA, Mc Devitt TC (2014) Pre-conditioning mesenchymal stromal cell spheroids for immunomodulatory paracrine factor secretion. Cytotherapy 16: 331-345.

30. Dromard C, Bourin P, Andre M, De Barros S, et al. (2011) Human adipose derived stroma/stem cells grow in serum-free medium as floating spheres. Exp Cell Res 317: 770-780.

31. Sasai Y (2013) Next-generation regenerative medicine: Organogenesis from stem cells in 3D culture. Cell Stem Cell 12: 520-530.

32. Sasai Y (2013) Cytosystems dynamics in self-organization of tissue architecture. Nature 493: 318-326.

33. Sart S, Tsai AC, Li Y, Ma T (2014) Three-dimensional aggregates of mesenchymal stem cells: Cellular mechanisms, biological properties, and applications. Tissue Eng Part B Rev 20: 365-380.

34. Schatten G, Smith J, Navara C, Park JH, Pedersen R (2005) Culture of human embryonic stem cells. Nat Methods 2: 455463.

35. Lin RZ, Chang HY (2008) Recent advances in three-dimensional multicellular spheroid culture for biomedical research. Biotechnol J 3: 1172-1184.

36. Achilli TM, Meyer J, Morgan JR (2012) Advances in the formation, use and understanding of multi-cellular spheroids. Expert Opin Biol Ther 12: 1347-1360.

37. Pastrana E, Silva-Vargas V, Doetsch F (2011) Eyes wide open: A critical review of sphere-formation as an assay for stem cells. Cell Stem Cell 8: 486-498.

38. Mueller-Klieser W (1987) Multicellular spheroids. A review on cellular aggregates in cancer research. J Cancer Res ClinOncol 113:101-122.

39. Petrenko Y, Sykova E, Kubinova S (2017) The therapeutic potential of three-dimensional multipotent mesenchymal stromal cell spheroids. Stem Cell Res Ther 8: 94-017-0558-6.

40. Murray J, Mynampati B, Fernandez S, Crandall M, Scott E (2019) Human osteogenic adipose-derived progenitor cells as a source of vascular endothelial growth factor. Journal of Bio Med Eng Res 3:1-14.

41. Murray J, Mynampati B, Crandall M, et al. (2019) Beyond a "pinch of this and a handful of that:" Using manufacturing standards for the isolation of human mesenchymal stem cells from adipose tissue- A novel point-of-care device. Journal of Stem Cell Reports 1:1-10.

42. Murray, JD, Doty, A, Jones, N, et al. (2019) A new ball for an old trick: Paramagnetic cell sorting of human mesenchymal stem cells from adipose tissue. Journal of Stem Cell Reports 1: 1-11.

43. Potapova IA, Brink PR, Cohen IS, Doronin SV (2008) Culturing of human mesenchymal stem cells as three-dimensional aggregates induces functional expression of CXCR4 that regulates adhesion to endothelial cells. J Biol Chem 283: 13100-13107.

44. Shin JY, Park J, Jang HK, et al. (2012) Efficient formation of cell spheroids using polymer nanofibers. Biotechnol Lett 34: 795803. 
45. Cheng NC, Wang S, Young TH (2012) The influence of spheroid formation of human adipose-derived stem cells on chitosan films on stemness and differentiation capabilities. Biomaterials 33: $1748-1758$.

46. Guo L, Zhou Y, Wang S, Wu Y (2014) Epigenetic changes of mesenchymal stem cells in three-dimensional (3D) spheroids. J Cell Mol Med 18: 2009-2019.

47. Petrenko Y, Sykova E, Kubinova S (2017) The therapeutic potential of three-dimensional multipotent mesenchymal stromal cell spheroids. Stem Cell Res Ther 8: 94-017-0558-6.

48. Ma D, Zhong C, Yao H, et al. (2011) Engineering injectable bone using bone marrow stromal cell aggregates. Stem Cells Dev 20: 989-999.

49. Webster RA, Blaber SP, Herbert BR, Wilkins MR, Vesey G (2012) The role of mesenchymal stem cells in veterinary therapeutics - a review. N Z Vet J 60:265-272.

50. Vidane AS, Zomer HD, Oliveira BM, et al. (2013) Reproductive stem cell differentiation: Extracellular matrix, tissue microenvironment, and growth factors direct the mesenchymal stem cell lineage commitment. Reprod Sci 20: 1137-1143.

51. Krampera M, Marconi S, Pasini A, et al. (2007) Induction of neural-like differentiation in human mesenchymal stem cells derived from bone marrow, fat, spleen and thymus. Bone 40: 382-390.

52. Aurich H, Sgodda M, Kaltwasser P, et al. (2009) Hepatocyte differentiation of mesenchymal stem cells from human adipose tissue in vitro promotes hepatic integration in vivo. Gut 58: 570581.

53. Engler AJ, Sen S, Sweeney HL, Discher DE (2006) Matrix elasticity directs stem cell lineage specification. Cell 126: $677-$ 689.

54. Cantinieaux D, Quertainmont R, Blacher S, et al. (2013) Conditioned medium from bone marrow-derived mesenchymal stem cells improves recovery after spinal cord injury in rats: An original strategy to avoid cell transplantation. PLoS One 8: e69515.

55. Insausti CL, Blanquer M, Garcia-Hernandez AM, Castellanos G, et al. (2014) Amniotic membrane-derived stem cells: Immunomodulatory properties and potential clinical application. Stem Cells Cloning 7: 53-63.

56. Smith CA, de la Fuente J, Pelaz B, Furlani EP, et al. (2010) The effect of static magnetic fields and tat peptides on cellular and nuclear uptake of magnetic nanoparticles. Biomaterials 31: 4392-4400.

57. Dejardin T, de la Fuente J, delPino P, et al. (2011) Influence of both a static magnetic field and penetratin on magnetic nanoparticle delivery into fibroblasts. Nanomedicine (Lond) 6:1719-
1731.

58. Lewis EE, Wheadon H, Lewis N, et al. (2016) A quiescent, regeneration-responsive tissue engineered mesenchymal stem cell bone marrow niche model via magnetic levitation. ACS Nano10: 8346-8354.

59. Souza GR, Molina JR, Raphael RM, et al. (2010) Three-dimensional tissue culture based on magnetic cell levitation. Nat Nano technol 5:291-296.

Submit your manuscript to a JScholar journal and benefit from:

ฯ Convenient online submission

ฯ Rigorous peer review

T Immediate publication on acceptance

ब Open access: articles freely available online

I High visibility within the field

I Better discount for your subsequent articles

Submit your manuscript at http://www.jscholaronline.org/submit-manuscript.php 